\title{
ACESSO À JUSTIÇA EM CAPPELLETTI/GARTH E BOAVENTURA DE SOUZA SANTOS
}

\section{ACCESS TO JUSTICE IN CAPPELLETTI / GARTH AND BOAVENTURA DE SOUSA SANTOS}

\author{
Antônio Hilário Aquilera Urquiza \\ Faculdade de Ciências Humanas (FACH), professor de Antropologia da Pós-graduação \\ em Direito (área de concentração em Direitos HUmanos) e da Pós-graduação em \\ Antropologia. Pesquisador PQ2 (CNPq).E-mail: hilarioaguilera@gmail.com
}

Adelson Luiz Correia

Mestrando da pós-graduação em Direito (área de concentração em Direitos Humanos), na Universidade Federal de Mato Grosso do Sul.E-mail:Luiz_Adelson@hotmail.com

Recebido em: 21/03/2018

Aprovado em: 10/07/2018

RESUMO: O acesso à justiça é um direito fundamental e humano marcado por barreiras na sua efetivação ao longo dos tempos. São obstáculos econômicos, sociais ou culturais, em conjunto ou isoladamente. A superação dessas dificuldades requer ampliação não apenas dos caminhos de acesso, mas, do próprio conceito de acesso à justiça. Cappelletti e Garth se aprofundaram nas problemáticas do acesso à justiça, e, no Relatório do Projeto Florença, amplamente difundido pela metáfora das três ondas, apresentam soluções e propostas. Boaventura de Souza Santos também se debruça sobre o assunto e propõe uma concepção democrática e inovadora em sua obra "Para uma revolução democrática da justiça". Ante a relevância das obras, o presente trabalho visa a encontrar os pontos de intersecção nas teorias de Cappelletti e Garth e Boaventura de Souza Santos e a contextualizar com a atual situação do acesso à justiça no Brasil, buscando compreender o reflexo das propostas na formação da concepção de justiça brasileira. A pesquisa é descritiva e bibliográfica e adota as obras citadas como marco teórico. Primeiramente, faz-se uma explanação sobre o Projeto Florença, destacando as barreiras e as soluções apontadas. A seguir, abordar-se a concepção revolucionária de acesso à justiça de Boaventura de Souza Santos, destacando os pontos de encontro entre as referidas ideias. Por fim, traça-se um panorama da concepção tradicional à nova concepção de acesso à justiça no cenário jurídico brasileiro sob a influência das reformas apontadas pelos pesquisadores.

Palavras-Chave: Acesso à Justiça. Reformas. Poder Judiciário.

ABSTRACT:Access to justice is a fundamental and human right marked by barriers in its implementation over time. They are economic, social or cultural obstacles, together or in isolation. Overcoming these difficulties requires not only the access routes but also the concept of access to justice. Cappelletti and Garth elaborated on the problems of access to justice, and in the Project Report Florence, widely disseminated by the metaphor of the three waves, present solutions and proposals. Boaventura de Sousa Santos also focuses on the subject and proposes a democratic and innovative conception in his work "Towards a democratic revolution of justice". Given the relevance of the works, the present work aims to find the points of intersection in the theories of Cappelletti and Garth and Boaventura de Sousa Santos and to contextualize with the 
current situation of access to justice in Brazil, seeking to understand the reflection of the proposals in the formation of conception of Brazilian justice. The research is descriptive and bibliographical and adopts the works cited as theoretical framework. Firstly, an explanation is made of the Florence Project, highlighting the barriers and the solutions pointed out. Next, we approach the revolutionary conception of access to justice of Boaventura de Souza Santos, highlighting the points of encounter between these ideas. Finally, an overview of the traditional conception of the new conception of access to justice in the Brazilian legal scenario is presented, influenced by the reforms pointed out by the researchers.

Key Words: Access to justice; reforms; judicial power.

SUMÁRIO: Introdução; 1. O Acesso à Justiça em Cappelletti e Garth: barreiras e ondas reformistas de solução; 2. O acesso à justiça em Boaventura de Souza Santos: para uma revolução democrática da justiça; 3. Cappelletti/Garth e Boaventura: continuidade e complementariedade de ideias; $4 \mathrm{O}$ acesso à justiça no Brasil: da concepção tradicional à Constituição de 1988; Conclusão; Referências Bibliográficas.

\section{INTRODUÇÃO}

A busca pela efetivação da justiça tem incomodado gerações e animado grupos sociais ao longo dos séculos sem, contudo, deixar de ser atual. Não por acaso o acesso à justiça foi sublimado ao patamar de direito humano, presente em instrumentos jurídicos de envergadura internacional.

Como sinônimo de acesso aos tribunais, o direito de acesso à justiça foi sacralizado nos principais tratados, pactos e convenções internacionais sobre direitos humanos. A Declaração Universal dos Direitos do Homem que dispõe expressamente que "VIII. Todo homem tem direito a receber, dos tribunais nacionais competentes, remédio efetivo para os atos que violem os direitos fundamentais que lhe sejam reconhecidos pela constituição ou pela lei” (ONU, 1948).

$\mathrm{O}$ direito de acesso à justiça também foi erigido como direito humano pela Convenção Europeia para a Salvaguarda dos Direitos do Homem e das Liberdades Fundamentais (1950), pelo Pacto Internacional de Direitos Civis e Políticos (1966) e pelo Pacto de São José da Costa Rica (1969).

A expressão Justiça é semanticamente aberta, plástica o bastante para se amoldar as mais variadas concepções políticas, filosóficas e sociológicas, o que denota que a busca pela Justiça é imanente à pessoa humana e, de uma forma ou de outra, democraticamente ou não, em maior ou menor medida, alicerça a construção de toda forma de organização social.

Embora seja muito mais amplo, o conceito de acesso à justiça, não raras vezes, é visto sob a lente reducionista do acesso ao Judiciário. Constata-se, pois, esse reducionismo à vista dos sinônimos dados ao princípio, tais como "acesso ao Judiciário" ou "direito de ação".

Conceituar a expressão acesso à justiça não é uma tarefa fácil. O fato de haver várias denominações para o mesmo princípio revela essa dificuldade. Fica evidente também o reducionismo de algumas expressões como acesso ao Judiciário ou direito de ação.

Nos últimos anos tem-se notado uma nova delineação do próprio conceito de acesso à justiça, na qual se pretende superar a ideia de acesso ao Judiciário como acesso à justiça, embora, ainda se note que visão reducionista é muito presente em nosso sistema de tutela jurídica.

Mauro Cappelletti e Bryan Garth (1988), conduziram um dos mais importantes estudos sobre o acesso à justiço, o Projeto Florença (Florence Project), cujo relatório deu origem à obra traduzida para o português com título "Acesso à justiça". Na obra são apontadas várias barreiras no acesso à justiça, bem como surgimento de reformas como "ondas de acesso à justiça", com propostas de soluções para os referidos obstáculos. Os autores descrevem o acesso à justiça como "o requisito fundamental - o mais básico dos direitos humanos - de um sistema jurídico moderno 
e igualitário que pretenda garantir, e não só proclamar direitos" (CAPPELLETTI; GARTH, 1988, p. 12).

Em 2007, quase meio século depois do estudo de Cappelletti e Garth, é publicada a obra "Para uma revolução democrática da justiça", de Boaventura de Souza Santos. Não é nessa obra que Boaventura inaugura seus debates sobre o acesso à justiça, contudo a escolha da obra como marco teórico se justifica pelo objetivo de destacar os pontos de toque entre a concepção de acesso à justiça de Cappelletti e Garth (1988) e a defendida por Boaventura de Souza Santos (2007).

As obras desses autores têm influenciado o sistema judiciário de vários países, e não é diferente no Brasil, que já passou por diversas reformas com o objetivo de ampliar o acesso à justiça.

A pesquisa é descritiva e bibliográfica, conforme critérios de classificação de Vergara (1988). Inicialmente é feita uma explanação dos estudos de Cappelletti e Garth (1988). Adiante, aborda-se a proposta de revolução da justiça de Boaventura de Souza Santos (2007) e segue-se com cotejamento dos pontos de intersecção entre as teorias dos autores citados. Por fim, traça-se um panorama da concepção e do acesso à justiça no Brasil, bem como da ampliação do conceito de acesso à justiça no sistema judiciário.

\section{ACESSO À JUSTIÇA EM CAPPELLETTI E GARTH: BARREIRAS E ONDAS REFORMISTAS}

O Florence Project (Projeto Florença) talvez seja o trabalho mais difundido no meio acadêmico sobre o acesso à justiça. Cappelletti e Garth (1988) ao se debruçarem sobre o tema do acesso à justiça, os pesquisadores reconheceram a dificuldade em se definir a expressão acesso à justiça. Contudo, concordaram que a acessibilidade de todos a um sistema pelo qual "podem reivindicar seus direitos e/ou resolver seus litígios sob os auspícios do Estado" e a produção de "resultados que sejam individual e socialmente justos" são duas finalidades do acesso à Justiça (CAPPELLETTI; GARTH, 1988, p. 08).

$\mathrm{O}$ direito de acesso à justiça é classificado pelos autores como "o mais básico dos direitos", pois não tem sentido a ampliação e atribuição de outros direitos sem que haja mecanismos de reivindicação. É cediço que, por vezes, o acesso a outros direitos é precedido da efetivação do direito de acesso à justiça (CAPPELLETTI; GARTH, 1988, p. 11-12).

Os autores chamam a atenção para o enfoque processualista do acesso à justiça, advertindo que os juízes precisam reconhecer o caráter social das técnicas processuais; que os tribunais não são única forma de solução de conflitos; que a utilização dos meios alternativos deve incentivada e encorajada, pois influenciam na forma de operação da lei substantiva, gerando benefício e impacto social. Asseveram, ainda, que os processualistas devem ampliar suas pesquisas para além dos tribunais, utilizando métodos de análise da sociologia, da política, da psicologia e da economia (CAPPELLETTI; GARTH, 1988).

Ainda que crescente aceitação do efetivo acesso à justiça como um direito básico nas sociedades modernas, a expressão efetividade é dotada de certa vagueza conceitual. A efetividade perfeita, "poderia ser expressa como "igualdade de armas", considerando apenas os "méritos jurídicos relativos às partes antagônicas", não se considerando "diferenças que sejam estranhas ao Direito" (CAPPELLETI; GARTH, 1998, p. 15).

. É utópica a ideia de igualdade perfeita, pois nunca se conseguirá afastar completamente as diferenças entre as partes. A questão que se coloca, então, é descobrir até onde prosseguir na busca de um objetivo impossível e a que custo. Em outras palavras, quantos dos obstáculos ao acesso à justiça podem ser superados?

Zaganelli (2016) classifica as barreiras apontadas por Cappelletti e Garth (1988) como econômicas, organizacionais e processuais. Com efeito, são fatores multifacetários. 
A primeira barreira é representada pelo elevado valor das custas em geral. $\mathrm{O}$ acesso ao Judiciário já é marcado pelo alto custo. Ainda que o Estado suportasse as despesas para manutenção do aparelho judicial, as partes ainda precisavam arcar com despesas de honorários advocatícios, além das custas judiciais, que servem para amortizar os custos suportados pelo Estado. O problema das custas se agravava em relação às pequenas causas, uma vez que o custo do processo formal podia esvaziar o pedido e reduzir a causa a uma futilidade (CAPPELLETTI; GARTH, 1988).

Outro fator impeditivo eram os honorários advocatícios. Se de um lado o sistema americano se mostrava um risco por não obrigar o vencido a pagar os custos de honorários advocatícios da parte vencedora; de outro, o sistema de sucumbência praticado em muitos países acabava sendo um óbice ainda maior. Com efeito, o custo dos honorários se tornava um empecilho incontornável, "na medida em que uma ou ambas as partes devem suportá-lo" (CAPPELLETTI; GARTH, 1988, p. 18).

A barreira econômica não se reduz apenas em custas judiciais e honorários advocatícios. $\mathrm{O}$ fator tempo também integra o contexto econômico na medida implica em corrosão inflacionária e deságio do bem da vida durante o curso prolongado do processo.

Também se verificam fatores socioculturais, tais como capacidade econômica; educação; meio e status social; capacitação pessoal e de frequência de contato com as instituições estatais de justiça. Os recursos financeiros são vitais para defender ou propor uma demanda, quem os tem consegue litigar e esperar o encerramento do processo, além de poder contratar profissionais qualificados para representa-los. A capacitação pessoal está ligada à aptidão para reconhecer um direito, que pode decorrer até mesmo da ausência de informação, problema que afeta, em regra, a camada mais pobre da sociedade. A disposição psicológica é um outro obstáculo: ainda que conhecedores dos seus direitos, muitas pessoas optam por não reivindicálos, em razão do formalismo que pode ser assustador para pessoas menos instruídas. Ainda nesse contexto, insere-se a questão dos litigantes habituais e eventuais. Aqueles estariam em vantagem em relação a estes por terem mais experiência com o direito; por terem economia de escala em razão da quantidade de casos; por terem mais oportunidades de manterem relações informais com os magistrados dentre outras (CAPPELLETTI; GARTH, 1988).

Os obstáculos organizacionais são verificados em relação aos assuntos de interesse difuso - meio ambiente, proteção ao consumidor e outros (ZAGANELLI, 2016). Este entrave decorre da dificuldade de inviabilizar a propositura de ação de defesa de direito individual frente prejuízos oriundos de danos coletivos. A fragmentação equipara o interesse individual ao problema das pequenas causas, de modo que as dificuldades inviabilizam o exercício do direito. A reunião de interessados seria a forma de contornar os obstáculos, não fosse a dispersão entre os prejudicados, dificultando a organização para demandar em grupo (CAPPELLETTI, GARTH, 1988).

Por fim, os obstáculos de caráter processual representam "morosidade do processo, a sobrecarga no sistema judicial, o formalismo exacerbado, a falta de juízes e gestão, os quais dificultam a efetividade nas resoluções de conflitos" (ZAGANELLI, 2016, p. 187).

Para a superação ou contorno dessas barreiras, Cappelletti e Garth (1988) apontam o surgimento de ondas reformistas de acesso à justiça. A primeira onda "foi a assistência judiciária"; a segunda onda estava voltada a representação jurídica para os interesses difusos e a terceira onda foi o enfoque de acesso à justiça, buscando "atacar as barreiras ao acesso de modo mais articulado e compreensivo" (CAPPELLETTI; GARTH, 1988, p. 31).

A primeira onda representa os esforços empreendidos pelos países ocidentais em ofertar assistência jurídica aos pobres, através da criação de sistemas como o judicare (advogado particulares pagos pelo Estado), o do advogado contratado pelo Estado (empregado) e o modelo combinado, que misturava o Judicare com o modelo de advogado contratado pelo Estado. Outras 
medidas foram isenção de custas judiciais (FRANÇA 1977) e adoção da oralidade nos processos (CAPPELLETTI; GARTH, 1988).

A segunda onda foi voltada às questões de interesses difusos e promoveu reformas no processo, passando a albergar interesses coletivos e não apenas individuais como imperava.

É na terceira onda, a mais difundida, que os autores apresentam uma ampliação no acesso, sob "o novo enfoque do acesso à justiça". O novo enfoque sugere não o abandono das soluções trazidas pelas ondas anteriores, mas, sim, tê-las como algumas de várias possibilidades para melhorar o acesso. A terceira onda "centra sua atenção no conjunto geral de instituições e mecanismo, pessoas e procedimentos utilizados para processar e mesmo prevenir disputas nas sociedades modernas" (CAPPELLETTI; GARTH, 1988, p. 67-68).

O ideário de acesso à justiça defendido por Cappelletti e Garth (1988), no contexto da terceira onda, será mais bem explorado à frente, quando da comparação com a teoria de revolução democrática da justiça de Boaventura de Souza Santos (2007).

\section{O ACESSO À JUSTIÇA EM BOAVENTURA DE SOUZA SANTOS: PARA UMA REVOLUÇÃO DEMOCRÁTICA DA JUSTIÇA}

Publicada em 2007, a obra "Para uma revolução democrática da justiça" é fruto de uma palestra de Boaventura de Souza Santos realizada em Brasília, a convite do então Ministro de Justiça, Tarso Genro, sobre a democratização do acesso à justiça. Boaventura de Souza Santos (2007, p. 4) assevera que diante das tensões e disjunções entre justiça procedimental e material, "o acesso à justiça é uma janela analítica privilegiada para se discutir a reinvenção das bases teóricas, práticas e políticas de um repensar radical do direito".

Segundo Boaventura de Souza Santos (2007, p. 6), somos "herdeiros das promessas da modernidade", uma fantasia que na verdade se traduz em problemas de desigualdade, de exclusão social, de degradação ecológica, ao invés da igualdade, da liberdade e fraternidade prometida. E diante desse cenário, no qual se verifica o fracasso de soluções apresentadas pelo liberalismo e socialismo, "podemo-nos reconciliar com a sociedade em que vivemos e celebrar o que existe meramente como existe" ou "submetê-la a uma crítica radical, transgredindo as fronteiras sociais, culturais, políticas, epistemológicas e teóricas de forma a cumprir o potencial emancipatório das promessas da modernidade" (SANTOS, 2007, p. 6).

Só faz sentido revolucionar o direito e a justiça se a revolução for ampla o suficiente para democratizar o Estado e a própria sociedade. A revolução democrática da justiça é o pressuposto do direito emancipatório, que perpassa pela valorização da diversidade jurídica do mundo como mola propulsora do pensamento jurídico crítico. A consciência cosmopolita da existência de diferentes imaginários e práticas do direito no mundo e o inconformismo em face do desperdício da experiência da luta por direitos mais justos, mais acessíveis e mais inteligíveis é o elemento subjetivo que baliza a ideia da obra. É com base nesses pressupostos que Boaventura de Souza Santos (2007, p. 8) defende uma "análise extensiva, crítica e criativa dos principais vetores de refundação democrática do papel do direito e da justiça". Propõe uma reforma ampla, que envolve não só aparelho estatal judiciário, mas o próprio repensar das concepções dominantes do direito, que se assenta em três pressupostos: a) revolução democrática do Estado; b) revolução democrática da sociedade e c) revolução da justiça.

Para o direito ser democraticamente exercido, a cultura na qual se insere também deve ser democrática, o que nem sempre acontece; e o direito e a prática ficam distantes entre si, levando a um descrédito do papel do direito na construção da democracia, o que, por sua, vez tende a aumentar o crescimento das desigualdades sociais e a acentuar a consciência social de sua injustiça. Contudo, se por um lado as desigualdades sociais têm aumentado; por outro, progressivamente as classes populares têm tomado consciência dessas desigualdades e das 
violações de seus direitos; e não têm ficado inertes. Elas se organizam individual ou coletivamente para reclamar seus direitos (SANTOS, 2007).

Nas palavras de Boaventura de Souza Santos (2007, p. 24) sua concepção de acesso "irá mudar a justiça que se tem acesso", mediante um sistema de transformação recíproca, jurídicopolítica, cujos principais vetores são: 1) profundas reformas processuais; 2) novos mecanismos e novos protagonismos no acesso ao direito e à justiça; 3) o velho e o novo pluralismo jurídico; 4) nova organização e gestão judiciárias; 5) revolução na formação profissional: da faculdade à formação permanente; 6) novas concepções de independência judicial; 7) relação do poder judicial mais transparente com o poder público e a mídia; 8) cultura jurídica democrática e não corporativa.

As transformações são necessárias, e só em conjunto poderão mudar o cenário jurídico e judiciário. Boaventura de Souza Santos (2007) reconhece que o sistema judicial não é capaz, sozinho, de solucionar todas as injustiças sociais, mas adverte que ele deve assumir sua cota de responsabilidade na busca por soluções, sob pena de se tornar irrelevante social e politicamente. Se por um lado sua omissão o isola, por sua atuação o torna democrático e articulado com outras organizações e instituições sociais.

Tendo por objetivo encontrar os pontos de intersecção na abordagem da concepção de acesso à justiça de Cappelletti e Garth e de Boaventura de Souza Santos, não é escopo deste trabalho o esgotamento das referidas obras. Sendo assim, a partir do panorama já esboçado das ideias dos autores, passa-se a identificar os pontos em que os pensamentos se tocam.

\section{CAPPELLETTI/GARTH E BOAVENTURA: UMA RELAÇÂO DE CONTINUIDADE E DE COMPLEMENTARIEDADE DE IDEIAS}

A teoria dominante nos Estados burgueses do liberalismo dos séculos XVIII e XIX, dominados pela filosofia do individualismo, condenava a interferência Estatal nas relações individuais, de sorte que os direitos naturais não necessitavam de uma atuação positiva por parte dos Estados para sua proteção. No sistema laissez-faire, oacesso à justiça estatalera considerado um direito natural, embora seu exercício estivesse inviabilizado para os pobres em razão do seu alto custo, condenando-o ao acesso meramente formal. $\mathrm{O}$ acesso efetivo só ficava ao alcance daqueles que detinham condições financeiras de arcar com os custos de se movimentar o Judiciário (CAPPELLETTI; GARTH 1988, p. 09).

É no contexto da passagem do liberalismo para o welfare State (Estado do Bem-estar Social), com a promulgação de constituições modernas garantindo novos direitos, como o direito ao trabalho, à saúde, à segurança e à educação que se percebeu a necessidade da interferência do Estado para assegurar a nova categoria de direitos.

$\mathrm{O}$ direito ao acesso efetivo à justiça ganhou particular atenção à medida que as reformas do welfare State armaram os indivíduos de novos direitos substantivos como consumidores, locatários, empregados e como cidadão (CAPPELLETTI; GARTH, 1998).

Guardadas as devidas proporções, verifica-se que, se em Cappelletti e Garth o acesso à justiça entrou em pauta pela expansão do welfare State; em Boaventura de Souza Santos (2007) é justamente pelo fato do desmantelamento do Estado Social; além da necessidade de garantir a estabilidade das regras de mercado e dos contratos.

O neoliberalismo "não garantiu o crescimento, aumentou tremendamente as desigualdades sociais, a vulnerabilidade, a insegurança e a incerteza na vida das classes populares, para além de fomentar uma cultua de indiferença à degradação ecológica" (SANTOS, 2007, p. 20).

É nesse contexto que Boaventura de Souza Santos (2007) verifica dois campos em relação ao judiciário: o hegemônico e o contra hegemônico. O primeiro concentra a grande parte das reformas do sistema judiciário por todo o mundo e tem como protagonistas o Banco Mundial, 
o Fundo Monetário Internacional, o Banco Interamericano de Desenvolvimento e etc. Esse "é o campo dos negócios, dos interesses econômicos, que reclama por um sistema judiciário eficiente, rápido, que permita a previsibilidade dos negócios, dê segurança jurídica e garanta a salvaguarda dos direitos de propriedade" (SANTOS, 2007, p. 20-21).

Já o contra hegemônico é a trincheira dos cidadãos conscientes de que os "processos de mudança constitucional lhes deram direitos significativos e que, por isso, veem no direito e nos tribunais um instrumento importante para fazer reivindicar os seus direitos e suas justas aspirações a serem incluídos no contrato social" (SANTOS, 2007, p. 21).

Percebe-se, aqui, um primeiro ponto de encontro entre o pensamento de Cappelletti e Garth (1988) e de Boaventura de Souza Santos (2007): a preocupação com o acesso ao direito e à justiça de algumas classes sociais e indivíduos que estão excluídos da sociedade e, consequentemente, também estão postos à margem do sistema jurídico como um todo. Contudo, não é o ponto central das ideias dos autores, que propõem uma ampliação na concepção de acesso, para dentro e fora dos tribunais.

Cappelletti e Garth (1988) reconhecem a importância das reformas empreendidas, mormente das duas primeiras ondas (assistência judiciária e representação jurídica para os interesses difusos), que deram representação para interesses antes não representados ou não devidamente representados. Mas sugerem um novo enfoque de acesso à justiça (a terceira onda), na qual se concentra a atenção no conjunto de instituições, mecanismos, pessoas e procedimentos utilizados para processar e ou mesmo prevenir disputas. Não se sugere o abandono das técnicas das ondas anteriores, mas, sim, seu tratamento apenas como possibilidades de melhoria no acesso à justiça (CAPPELLETTI; GARTH, 1998).

A terceira onda, o "novo enfoque de acesso à justiça" apresentado por Cappelletti e Garth (1988), sugere uma variedade de reformas que vai muito além da representação judicial. Incluem os procedimentos, a estrutura dos tribunais, a criação de novos tribunais, a atuação de pessoas leigas ou para profissionais, modificação do direito substantivo para evitar litígios ou facilitar sua solução, utilização de mecanismos privados ou informais para solucionar litígios, adequação do processo civil ao tipo de litígio.

Cappelletti e Garth (1988) apresentam em seu relatório várias reformas no sentido de melhorar e modernizar os tribunais e seus procedimentos: a oralidade; a livre apreciação da prova; a concentração do procedimento; o contato direto entre juízes, partes e testemunhas. Ainda no âmbito dos tribunais, são apresentadas outras reformas, tais como a isenção de custas na França, o "Modelo Stuttgart" germânico, cujo procedimento envolve "as partes, advogados e juízes, num diálogo oral e ativo sobre os fatos e sobre o direito" (CAPPELLETTI; GARTH, 1988, p. 29).

Meios alternativos de solução de litígios já bastantes conhecidos tais como o juízo arbitral e conciliação também estão no raio de abrangência das reformas. A criação de tribunais especializados para determinados tipos de demanda seria um método essencial para facilitar o acesso de determinados indivíduos e classes. Essa técnica possibilita a solução de causas com agilidade e custo reduzido, além de aliviar o congestionamento e o atraso dos tribunais. Nessa linha de raciocínio se encaixam juizados especiais (pequenas causas), tribunais de vizinhança e os tribunais especiais para demandas de consumidores.

Destacam-se, também, mudanças nos métodos utilizados para a prestação de serviços jurídicos. Nesse ponto ganha destaque a atuação de "parajurídicos" (assistentes jurídicos com diversos graus de treinamento em Direito). São profissionais preparados para serviços jurídicos que dispensam a atuação de advogados altamente treinados, como é o caso dos "Rcchtspfleger" (funcionário-juiz para profissional) alemão ou os "McKenzie Men" da Inglaterra. Cappelletti e Garth (1988) chamam atenção também para o desenvolvimento de planos de assistência jurídica mediante convênios ou grupos. A proposta funciona como um seguro (plano de convênio para 
serviços jurídicos), onde os interessados pagam o prêmio para terem a prestação de serviços jurídicos pré-determinados quando necessários.

Para fechar as propostas apresentas por Cappelletti e Garth (1988, p. 55) no contexto da terceira onda, destaca-se a necessidade de simplificação do direito: "Se a lei é mais compreensível, ela se torna mais acessível às pessoas comuns". A simplificação do direito possibilita que as pessoas cumpram as exigências para utilização dos instrumentos jurídicos à sua disposição. Exemplos dessa reforma são a exclusão da averiguação da culpa nos casos de divórcio e estabelecimento da responsabilidade objetiva. Essas medidas reduzem o custo e a duração do litígio, além de aliviar a sobrecarga do judiciário.

As similitudes entre as propostas apresentadas por Cappelletti e Garth (1988) e as de Boaventura de Souza Santos (2007) são encontradas no contexto da terceira onda. A partir do catálogo de reformas de Cappelletti e Garth que notamos o encontro de algumas ideias.

Boaventura de Souza Santos sugere inovações institucionais, entre as quais se incluem reformas processuais e na estrutura e gestão dos tribunais, onde se verifica uma morosidade sistêmica (a decorrente da sobrecarga de trabalho, do excesso de burocracia, do positivismo e do legalismo) e uma morosidade ativa (interposição de obstáculos para impedir o andamento do processo e o desfeche do caso, por partes de todos os operadores do direito e terceiros envolvidos no caso). Defende "a alteração dos métodos de trabalho, uma nova organização interna dos tribunais, maior eficácia na gestão de recursos humanos e materiais e de fluxos processuais e uma melhor articulação dos tribunais com outros serviços complementares da justiça" (SANTOS, 2007, p. 52); e chama a atenção para os juizados especiais, que, no Brasil, foram alternativas para desafogar o sistema judicial.

Boaventura de Souza Santos (2007) apresenta vários instrumentos de acesso ao direito e à justiça, potencialmente capazes de universalizar o acesso, tais como as defensorias públicas, as promotoras legais populares, as assessorias jurídicas universitárias populares, a capacitação de líderes comunitários e a advocacia popular. Para Boaventura de Souza Santos (2007, p. 46), “esta profusão de iniciativas, alternativas ou críticas partilham um denominador com grande potencial de transformação das práticas tradicionais de acesso à justiça: a capacitação jurídica do cidadão".

Ainda no contexto das inovações institucionais, Boaventura de Souza Santos (2007, p. 47) observa que a ideia central é a "valorização de experiências e estratégias que fomentem a aproximação entre a justiça e a cidadania". Nessa linha, destacam-se inciativas no cenário brasileiro como a justiça itinerante, a justiça comunitária, os meios alternativos de resolução de litígios como a mediação, conciliação judicial e extrajudicial, a justiça restaurativa e os juizados especiais.

Guardadas as devidas proporções e especificações, as reformas apontadas por Cappelletti e Garth (1988) no âmbito da terceira onda, que seria um novo enfoque no acesso à justiça, basicamente se repetem em Boaventura de Souza Santos (2007), como reformas processuais, alteração na estrutura dos tribunais, utilização de novos mecanismos como, especialização de tribunais, atuação de para profissionais e novas técnicas de resolução de conflitos como conciliação, mediação e arbitragem.

Um dos aspectos do pensamento de Boaventura de Souza Santos (2007) ajuda a complementar o conceito de acesso à justiça em Cappelletti e Garth (1988) é o ensino do direito e a formação profissional.

O sistema judicial, bem como o contexto social, político e cultural em que se operam as funções judiciais estão em transformação. "A despolitização da regulação social, o aumento das desigualdades sociais, a globalização das sociedades são realidades que criam um novo contexto a exigir novas funções à prática jurídica" (SANTOS, 2007, p. 54), e nesse contexto o ensino do direito e a formação, especialmente a formação continuada, ganham destaque, não apenas na eficácia do sistema judicial, mas principalmente, na sua transformação (SANTOS, 2007). 
Boaventura de Souza Santos (2007) acredita que a concretização do projeto de refundação democrática da justiça passa pelo ensino e formação dos operadores do direito, envolvendo funcionários, membros do ministério públicos, juízes, defensores, advogados. A formação continuada assume especial importância nesse projeto, a exemplo da Alemanha, onde os juízes se submetem a cursos de formação antes de aplicar qualquer inovação legislativa, pois a formação inadequada pode resultar na aplicação errônea da lei.

A formação continuada teria o condão de mudar o desenho da magistratura, que, com algumas, ressalvas, é dominada por uma cultura normativista e técnico-burocrática, assentada em três grandes ideias: autonomia do direito; concepção restritiva do direito e concepção burocrática ou administrativa dos processos, que se manifestam através da prioridade do direito civil e penal (dogma da autonomia do direito civil e penal como imagem da autonomia do direito em geral); da cultura generalista (ideia de que o magistrado possui todas as competências pelo simples fato de ser magistrado); da desresponsabilização sistêmica (tratar a autonomia do direito como se fosse autonomia do aplicador, desresponsabilizando-o perante os maus resultados do desempenho do sistema judicial); do privilégio do poder (cultura autoritária que coloca os agentes do poder em patamar diferente dos cidadãos comuns, com privilégios perante a justiça); do refúgio burocrático (preferência por tudo que é institucional e burocraticamente formatado); da sociedade longe (ser competente para interpretar o direito e incompetente para interpretar a realidade social) e da independência como autossuficiência (confusão entre independência e individualismo autossuficiente. Aversão à formação de equipe, à colaboração interdisciplinar e ao aprendizado com outros saberes) (SANTOS, 2007).

Essa abordagem também inclui a mudança do paradigma jurídico-dogmático que impera no ensino das faculdades de direito. Para Boaventura de Souza Santos (2007, p. 58), "as faculdades de direito acabaram criando uma cultura de extrema indiferença ou exterioridade do direito diante das mudanças experimentadas pela sociedade".

É preciso que haja uma revolução das faculdades de direito, substituindo a cultura técnico-burocrática por uma cultura técnico-democrática. O pressuposto dessa revolução está na formação pedagógica adequada dos professores e na implementação satisfatória do ensino, da pesquisa e da extensão. Boaventura de Souza Santos (2007) critica o fato de muitos professores dos cursos de direito exercerem a docência como atividade profissional secundária. "Um professor sem nenhuma preparação pedagógica e sem nenhuma reflexão crítica acerca da sua ação docente torna-se um improvisador" (SANTOS, 2007, p. 60). "Essa antipedagogia asfixiante subjaz ainda hoje à grande parte do ensino jurídico, não se podendo esperar dela nenhuma preparação para práticas exigentes de cidadania e de democracia" (SANTOS, 2007, p. 60).

O pensamento de Boaventura de Souza Santos (2007) mostra-se mais articulado e detalhado, mas, para fins deste trabalho, foram considerados apenas os aspectos nos quais se assemelham às propostas de Cappelletti e Garth (1988). A explanação da necessidade de mudança no formato de ensino e formação dos profissionais é apenas uma amostra de outras pautas para uma revolução democrática da justiça.

A exposição como posta cumpre o objetivo de comparar as reformas apresentadas por Cappelletti e Garth (1988), especialmente no contexto da terceira onda, e as de Boaventura de Souza Santos (2007), no contexto da revolução democrática da justiça.

Cumpre agora contextualizar o quadro apresentado pelos autores e compreender o reflexo dessas propostas na formação da concepção de justiça no contexto brasileiro.

\section{O ACESSO À JUSTIÇA NO BRASIL: DA CONCEPÇÃO TRADICIONAL À NOVA CONSTITUIÇÃO DE 1988}

A Constituição de 1946 foi a primeira a incorporar em seu texto o direito de acesso à justiça, prevendo em seu art. 141, 4º, que "A lei não poderá excluir da apreciação do poder 
judiciário, qualquer lesão de direito individual”. Estava estabelecido o princípio inafastabilidade do controle jurisdicional, também denominado direito de ação, que foi repetido pelas constituições posteriores, tendo sofrido uma redução com o Ato Institucional $n^{\circ}$ 06/68 que "restringiu a garantia da inafastabilidade, vedando a jurisdição sobre os atos praticados pelo comando da revolução" (MOURA, 2007).

Já a Constituição Federal de 1988, por sua vez, adotou a Justiça como um valor norteador do Estado Democrático. No preâmbulo da Constituição Federal, considerado "uma proclamação de princípios, que tem o objetivo de mostrar as diretrizes políticas, filosóficas, e ideológicas do Estado que acabou de ser criado" (BULOS, 2011, p. 118), ficou assentado que se tratava da criação de um:

Estado Democrático, destinado a assegurar o exercício dos direitos sociais e individuais, a liberdade, a segurança, o bem-estar, o desenvolvimento, a igualdade e a justiça como valores supremos de uma sociedade fraterna, pluralista e sem preconceitos, fundada na harmonia social e comprometida, na ordem interna e internacional, com a solução pacífica das controvérsias. (BRASIL, 1988, grifo nosso).

O Supremo Tribunal Federal (STF) já foi instado a se manifestar algumas vezes sobre a normatividade do preâmbulo da Constituição de 1988. Nos autos da ADI 2.076/AC, de relatoria do Ministro Carlos Veloso, em que se discutia a obrigatoriedade de repetição preâmbulo nas constituições estaduais, ficou consignado no voto do relator que o preâmbulo não constitui norma central (BULOS, 2011, p. 119).

Na decisão proferida nos autos da ADI 2.649/DF, a Ministra Cármen Lúcia descreveu o preâmbulo como uma "explicitação dos valores que dominam a obra constitucional". (ADI 2.649/DF, voto da rel. min. Cármen Lúcia, j. 8-5-2008, P. DJE de 17-10-2008).

A discussão sobre a força normativa do preâmbulo quanto princípio da justiça guarda pouca relevância jurídica, posto o referido princípio não estar vinculado simplesmente à ideia de valor norteador. Está consagrado no texto constitucional de 1988, especificamente no art. $5^{\circ}$, XXXV, que veda à lei a exclusão da apreciação pelo Poder Judiciário de qualquer lesão ou ameaça a direito, espraiando sua força para além do catálogo de intenções constitucionais (CORREIA; RIBAS, 2017).

Além de um direito fundamental, também é um compõe o alicerce do Estado democrático de direito, considerado uma norma-princípio. Segundo Gontijo (2015, p. 18):

Em razão de sua qualificação como norma-princípio, estruturante do Estado Democrático, o direito à justiça pode ser enquadrado tanto como princípio constitucional estabelecido, extraído da previsão, no art. $1^{\circ}$ da Constituição, de que a 'República Federativa do Brasil [...] se constitui em Estado Democrático de Direito' quanto como princípio constitucional sensível, por meio da previsão, no art. 34, VII, letra a, de que a União não intervirá nos Estados e no Distrito Federal, salvo, dentre outros, para garantir a observância do regime democrático.

A busca pelo ideal de justiça foi incorporada aos objetivos fundamentais da Constituição Federal de 1988. De acordo com Moraes (2011) as autoridades constituídas devem observar os objetivos fundamentais, de acordo com as regras estabelecidas pela Constituição nos capítulos que se seguem ao rol de objetivos. Moraes $(2011$, p. 69) destaca ainda que:

$\mathrm{O}$ rol de objetivos do art. $3^{\circ}$ não é taxativo, tratando-se tão-somente da previsão de algumas finalidades a serem perseguidas pela República Federativa do Brasil. Os poderes públicos devem buscar os meios e instrumentos para promover condições de igualdade real e efetiva e não somente contentar-se com a 
igualdade formal, em respeito a um dos objetivos fundamentais da República: construir uma sociedade justa.

No Brasil, o tema acesso à justiça ganhou relevância nos anos 80, embora não pelas mesmas razões dos países desenvolvidos, como destaca Junqueira (1996, p. 1):

A princípio, poder-se-ia imaginar que o interesse dos pesquisadores brasileiros sobre este tema nos aos 80 estivesse diretamente relacionado com o movimento que havia começado da década anterior, em diversos países do mundo, o "acessto-justice” [...] no entanto, a análise das primeiras produções brasileiras revela que a principal questão naquele momento diferentemente do que ocorria nos demais países, sobretudo nos países centrais, não era a expansão do welfare state e a necessidade de se tornarem efetivos os novos direitos conquistados principalmente a partir dos anos 60 pelas 'minorias' étnicas e sexuais, mas sim a própria necessidade de se expandirem para o conjunto da população direitos básicos aos quais a maioria não tinha acesso tanto em função da tradição liberalindividualista do ordenamento jurídico brasileiro, como em razão da histórica marginalização sócio-econômica (sic) dos setores subalternizados e da exclusão político-jurídica provocada pelo regime pós-64 (grifo do autor).

O movimento do acesso à justiça no Brasil não acompanhou pari passu o movimento internacional. A Constituição de 1934 foi a primeira Constituição a prever a assistência judiciária, com isenção de emolumentos, custas, taxas e selos, sendo mantido tal benefício nas posteriores, com exceção da de 1937. A Constituição de 1988 deu um passo a mais que as anteriores, estabelecendo o direito à assistência jurídica integral e gratuita, que é mais abrangente, incluindo a prática de atos jurídicos extrajudiciais, aconselhamento jurídico, patrocínio da causa, além de ações coletivas e mediação (DANTAS, 2012).

No plano infraconstitucional, a Lei 1060/50, recepcionada pela Constituição de 1988, possibilitou que a parte economicamente vulnerável tivesse acesso ao Poder Judiciário, criando mecanismos para driblar barreiras econômicas. Já o Novo Código de Processo Civil trouxe algumas novidades, dentre outras, a possibilidade de requerimento de concessão da justiça gratuita em qualquer fase do processo; a concessão da gratuidade para litigantes pessoas físicas ou jurídicas; a impossibilidade de indeferir de plano o pedido de gratuidade.

À luz de uma concepção tradicional de acesso à justiça e sob a influência do estudo feito por Cappelletti e Garth (1988) nas últimas décadas foram feitas algumas mudanças no sistema judiciário brasileiro para facilitar o acesso ao Poder Judiciário, crendo-se que essa abertura seria suficiente para propiciar o acesso à justiça. Tradicionalmente o conceito de aceso à justiça é lido como acesso ao Judiciário. Essa concepção reducionista de acesso à justiça é verificada também nos instrumentos internacionais de proteção dos direitos humanos, que associam o acesso à justiça com acesso aos tribunais.

É de senso comum pensar em Poder Judiciário quando se refere ao acesso à justiça. $\mathrm{O}$ pensamento não está de todo equivocado. De fato, o acesso ao Judiciário também é uma forma de acesso à justiça, mas não a única (CESAR, 2002).

Segundo Grinover (2005, p. 303), o acesso à justiça "um dos mais caros aos olhos processualistas contemporâneos, não indica apenas o direito de aceder aos tribunais, mas também o de alcançar, por meio de um processo cercado das garantias do devido processo legal, a tutela efetiva dos direitos violados ou ameaçadas".

Já Dinamarco (2004) sentencia que a mera propositura da ação judicial não equivale a acesso à justiça. Acesso à justiça é acessar a ordem jurídica justa, é obter justiça substancial, e justiça substancial é receber uma solução tempestiva, bem formulada e que melhore a vida em relação ao bem pretendido. Dinamarco (2004) ressalta, ainda, que a exagerada valorização da 
tutela jurisdicional estatal pode levar ao menosprezo do valor de outros meios de pacificação social, o que deve ser evitado.

A partir dessas discussões, o próprio conceito de jurisdição passa a ter um novo sentido. Mancuso (2014, p. 153) afirma que:

A própria palavra jurisdição, que entre nós, tradicionalmente, aparece atrelada ao Estado, hoje comporta outra acepção, distanciando-se do sentido monopolístico oficial e abrindo-se para outras instâncias: dir-se-ia, outras estradas vicinais adrede pavimentadas para ofertar justiça por outros meios $e$ perante outros atores da cena judiciária, venha prevenido, ou, então, composto de modo justo, sob uma boa equação custo-benefício (grifo do autor).

Nos últimos anos, porém, apregoa-se uma nova leitura do acesso à justiça, não mais como o tradicional e vetusto acesso aos tribunais ou direito de ação, mas como o acesso efetivo à ordem jurídica justa. Nas lições de Watanabe (1988, p. 128) “a problemática do acesso à justiça não pode ser estudada nos acanhados limites do acesso aos órgãos judiciais já existentes. Não se trata apenas de possibilitar o acesso à Justiça enquanto instituição estatal e sim de viabilizar o acesso à ordem jurídica justa".

Nesse contexto de insuficiência, de morosidade, de ineficiência da jurisdição estatal e de alto custo aos cofres públicos, põe-se em xeque o modelo de monopólio estatal na distribuição da justiça, emergindo um modelo de jurisdição compartilhada, com a participação de outros atores que possibilitem meios alternativos de solução de conflitos, bem como da prevenção de litígios (MANCUSO, 2014).

A questão da morosidade do Judiciário está ligada à explosão da litigiosidade no Brasil nos últimos anos. Para Barroso (2008), a judicialização da vida não é um problema exclusivo do Estado brasileiro, mas fatores internos como redemocratização do Estado, a constitucionalização abrangente e o sistema de controle de constitucionalidade são algumas das causas da judicialização no Brasil.

A formação acadêmica dos operadores do Direito no brasileiro também exerce influência sobre o aumento da litigiosidade. Na mesma linha de Boaventura de Souza Santos Watanabe (2007) sustenta que poucas faculdades capacitam seus alunos para soluções alternativas à jurisdição, implicando na consolidação da cultura da sentença

Apesar de todos os percalços, Boaventura de Souza Santos (2007) considera que o crescimento das expectativas dos cidadãos em relação ao cumprimento de seus direitos consagrados na Constituição Federal de 1988, tende a transformar-se em um motivo de procura aos tribunais em razão da deficiente ou inexistente de políticas públicas, somados ao fato de a Constituição ter ampliado as estratégias e instituições para reclamar direitos, como "a ampliação da legitimidade para propositura de ações diretas de inconstitucionalidade, a possibilidade de as associações interporem ações em nome dos seus associados, a consagração da autonomia do ministério público e a opção por um modelo de assistência jurídica e promoção do acesso à justiça" (SANTOS, 2007, p. 14).

A obra "Para uma revolução democrática da justiça", que faz referência a estudos de Boaventura de Souza Santos (2007) sobre o acesso à justiça no Brasil, constata inovações no contexto brasileiro que vão ao encontro dessa nova demanda social: promotoras legais populares; assessorias jurídicas populares universitárias; capacitação jurídica de membros das comunidades; Justiça Comunitária Itinerante; fomento à resolução alternativa de conflitos feita pelo próprio poder Judiciário dentre outras.

Nesse cenário de releitura do direito de acesso à justiça e do sentido de jurisdição o movimento de desjudicialização tem ganhado espaço, inserindo novos personagens no cenário jurídico da busca pela efetivação da justiça. Para Bortz (2009, p. 106) "O envolvimento de outros atores jurídicos, capacitados para promover uma intervenção segura, estável e preventiva de 
litígios, faz-se fundamental para a manutenção do trafego jurídico num mundo que se torna mais e mais dinâmico".

Imperioso reconhecer que a complexidade e a dinâmica da sociedade atual requer essa releitura do acesso à justiça. É necessária a ampliação do conceito para além do acesso à justiça estatal. É preciso aceitar e encorajar novos participantes nesse processo democrático de acesso ao direito.

Essa inflexão no sistema de tutela jurídica brasileira está alinhada com o novo enfoque de acesso à justiça de Cappelletti e Garth (1988), sobretudo com a concepção de Boaventura de Souza Santos (2007), sob um viés pluralista edemocrático de resolução dos conflitos, mais adequado às necessidades da sociedade contemporânea, consubstanciado no acesso à ordem jurídica justa, pluralista, democrática e acessível a todos.

\section{CONCLUSÃO}

É possível notar que as ideias de Cappelletti e Garth (1988) e de Boaventura de Souza Santos (2007) caminham juntas e convergem para a abertura ampliação do acesso à justiça, albergando interesses individuais e de classes sociais geralmente excluídas. As ideias de Boaventura de Souza Santos (2007), no entanto, vão além das de Cappelletti e Garth (1988).

O Relatório de Florença concentra estudos sobre o acesso à justiça no contexto da expansão do Estado-providência. Mas o tempo da obra de Boaventura de Souza Santos (2007) é outro, com profundas mudanças no cenário político, jurídico e social, embora muitas das aspirações por acesso à justiça presentes no Relatório de Florença ainda se mantivessem.

Por ser posterior, ainda que não inaugure os debates de Boaventura de Souza Santos sobre o acesso à justiça, a obra "Para uma revolução democrática da justiça" surge em um cenário diferente daquele dos estudos de Cappelletti e Garth (1988).

Verifica-se que as ideias dos autores comungam, mas Boaventura de Souza Santos (2007) vai além, abordando a questão do acesso à justiça não apenas do ponto de vista da justiça estatal. Sugere uma nova maneira de ensinar, de aplicar e de se pensar o direito, que, consequentemente, reflete na maneira como se comportarão as instituições e operadores do direito e a própria sociedade em relação aos direitos de que é detentora.

As propostas reformistas, ainda que não cronologicamente, chegaram o território brasileiro. As duas primeiras ondas de Cappelletti e Garth (1988) também podem ser constatadas no cenário jurídico brasileiro sob a roupagem da assistência jurídica integral assegurada pela Constituição Federal. Mas é no confronto com as ideias do novo enfoque de justiça (terceira) onda e das ideias de democratização do Estado, democratização da sociedade e democratização da justiça que se percebe a quebra do dogma do acesso ao judiciário como única forma de acesso à justiça, questionando-se o monopólio estatal da jurisdição.

Surge então a ideia de jurisdição compartilhada, com novos mecanismos judiciais e extrajudiciais, com a participação de outros atores no cenário jurídico, com procedimentos menos engessados, redesenhando o acesso à justiça. Agora, significando o acesso a uma ordem jurídica justa, célere, tempestiva e democrática.

\section{REFERÊNCIAS}

BARROSO, Luis Roberto. Ano do STF: Judicialização, ativismo e legitimidade democrática, 2008. Consultor Jurídico. Disponível em: <http://www.conjur.com.br/2008-dez22/judicializacao_ativismo_legitimidade_democratica>. Acesso em: 18 mar. 2017. 
BORTZ, Marco Antonio Greco Bortz. A desjudicialização - um fenômeno histórico e global. Revista de direito notarial, ano1, $\mathrm{n}^{\circ}$ 1, São Paulo, Quartier Latin, jul- set 2009.

BRASIL. Constituição da República Federativa do Brasil de 1988. Disponível em: <http://www.planalto.gov.br/ccivil_03/Constituicao/Constituicao.htm>. Acesso em: 03 mar. dez. 2018.

Constituição da República Federativa do Brasil de 1946. Disponível em: <http://www.planalto.gov.br/ccivil_03/constituicao/constituicao46.htm>. Acesso em 10 mar. 2018.

assistência judiciária aos necessitados. Disponível em: <http://www.planalto.gov.br/ccivil_03/leis/L1060.htm>. Acesso em 10 mar. 2018.

Lei $\mathrm{n}^{\mathrm{o}}$ 13.105, de 16 de março de 2015. Código de Processo Civil. Disponível em: <http://www.planalto.gov.br/ccivil_03/_ato2015-2018/2015/lei/113105.htm>. Acesso em 10 mar. 2017.

$\begin{array}{ccccc} & \text { Supremo Tribunal Federal. ADI 2.649/DF, voto da rel. min. Cármen Lúcia, j. 8-5-2008, } \\ \text { P. } & \text { DJE } & \text { de } & 17-10-2008 . & \text { Disponível }\end{array}$ <http://redir.stf.jus.br/paginadorpub/paginador.jsp?docTP=AC\&docID=555517>. Acesso em: 05 mar. 2018.

BULOS, Uadi Lammêgo. Direito constitucional ao alcance de todos. 3. Ed. Ver. E atual. De acordo com a EC nº 66, de 13-7-2010 - São Paulo: Saraiva, 2011.

CAPPELLETTI, Mauro; GARTH, Bryant.Acesso à justica.Trad. Ellen Gracie Northfleet. Porto Alegre: Sérgio Antônio Fabris, 1988.

CESAR, Alexandre. Acesso à justiça e cidadania. Cuiabá: EdUFMT, 2002.

CORREIA, Adelson Luiz, RIBAS, Lídia Maria: Barreiras econômicas de acesso ao judiciário e o reflexo das medidas de superação no exercício da jurisdição estatal. InXIV Congresso Internacional de Direitos Humanos. Anais eletrônicos... Campo Grande, 2017. Disponível em http://cidh.sites.ufms.br/mais-sobre-nos/anais/ Acesso em: 16 mar. 2018.

DANTAS, Alexandre Fernandes. Acesso à Justiça e assistência jurídica gratuita no Brasil.Boletim Jurídico, Uberaba/MG, a. 13, no 955. Disponível em: <http://www.boletimjuridico.com.br/ doutrina/texto.asp?id=2484> Acesso em: 10 mar. 2018.

DINAMARCO, Cândido Rangel. Instituições de Direito Processual Civil. 5. Ed, revista e atualizada de acordo com a emenda constitucional n.45 de 8.12.2004. São Paulo: Malheiros, 2004.

GONTIJO; Danielly Cristina Araújo. O direito fundamental de acesso à justiça. São Paulo: LTr, 2015.

GRINOVER, Ada Pellegrini; et al. InTutela Coletiva: 20 anos da Lei da Ação Civil Pública e do Fundo de Defesa de Direitos Difusos, 15 anos do Código de Defesa do Consumidor / Paulo Henrique dos Santos Lucon (coord). - São Paulo: Aplas, 2006.

JUNQUEIRA, Eliane Botelho. Acesso à Justiça: um olhar retrospectivo. Revista Estudos Históricos, Rio de Janeiro, v. 9, n. 18, p. 389-402, dez. 1996. ISSN 2178-1494. Disponível em: <http://bibliotecadigital.fgv.br/ojs/index.php/reh/article/view/2025>. Acesso em: 05 mar. 2018. 
MANCUSO, Rodolfo de Camargo. A resolução dos conflitos e a função judicial no contemporâneo Estado de Direito. - 2 ed. ver., atual. e ampl. - São Paulo: Revista dos Tribunais, 2014.

MORAES, Alexandre de. Direitos humanos fundamentais: teoria geral, comentários aos arts. $1^{\circ}$ a $5^{\circ}$ da Constituição da República Federativa do Brasil, doutrina e jurisprudência/Alexandre de Moraes. - 9. Ed. São Paulo: Atlas, 2011.

MOURA, Caio Roberto Souto de. O princípio da inafastabilidade do controle jurisdicional e a Justiça Desportiva: um caso de antinomia jurídica. Revista de Doutrina TRF4, 2007.Disponível em:

<http://www.revistadoutrina.trf4.jus.br/index.htm?http://www.revistadoutrina.trf4.jus.br/artigos/e dicao016/Caio_Moura.htm>. Acesso em: 12 mar. 2018.

ORGANIZAÇÃ̃O DAS NAÇÕES UNIDAS - Declaração Universal dos Direitos Humanos, 1948. Disponível em: <https://nacoesunidas.org/direitoshumanos/declaracao/>. Acesso em: 17 mar. 2018.

SANTOS, Boaventura de Souza. Para uma revolução democrática da Justiça, 2007. Disponível em:

<http://sociologial.dominiotemporario.com/doc/REVOLUCAO_DEMOCRATICA_JUSTICA.pd f>. Acesso em: 10 fev. 2018.

VERGARA, Sylvia Constant. Projetos e relatórios de pesquisa em administração. $2^{\mathrm{a}}$ ed. São Paulo: Atlas, 1998.

WATANABE, Kazuo. A mentalidade e os Meios Alternativos de Solução de Conflitos no Brasil. In GRINOVER, Ada Pellegrini Grinover; LAGRASTA NETO, Caetano; WATANABE, Kazuo (Org). Mediação e gerenciamento do processo: revolução na prestação jurisdicional: guia prático para a instalação do setor de conciliação e mediação. São Paulo: Atlas, 2007, p. 6 - 10.

ZAGANELLI, Juliana. A (in)justiça do poder judiciário: o obstáculo econômico do acesso à justiça e o direito social à saúde. Revista de Direito Brasileira, São Paulo/SP,v. 15, n. 6, p. 185 199, set/dez. 2016. Disponível em: http://www.indexlaw.org/index.php/rdb/article/view/2959 Acesso em 17 mar. 2018. 